\title{
Delirium in HIV-infected patients admitted to acute medical wards post universal access to antiretrovirals in South Africa
}

\author{
C Day, ${ }^{1} \mathrm{MB}$ BCh, FCP (SA); K Manning, ${ }^{1} \mathrm{MSc}$ (Med); F Abdullah, ${ }^{1} \mathrm{FCP}(\mathrm{SA}) ; \mathrm{K}$ James, ${ }^{2} \mathrm{PhD}$; L Grace, ${ }^{2} \mathrm{PhD}$; C April, ${ }^{1} \mathrm{MB}$ ChB; \\ G Calligaro, ${ }^{1}$ FCP (SA); M Combrinck, ${ }^{1}$ FCP (SA); P Raubenheimer, ${ }^{1}$ FCP (SA); J G Peter, ${ }^{1,3,4}$ FCP (SA) \\ ${ }^{1}$ Division of General Medicine, Department of Medicine, Groote Schuur Hospital and Faculty of Health Sciences, University of Cape Town, \\ South Africa \\ ${ }^{2}$ Division of Geriatric Medicine, Department of Medicine, Groote Schuur Hospital and Faculty of Health Sciences, University of Cape Town, \\ South Africa \\ ${ }^{3}$ Division of Allergy and Clinical Immunology, Department of Medicine, Groote Schuur Hospital and Faculty of Health Sciences, University of \\ Cape Town, South Africa \\ ${ }^{4}$ Allergy and Immunology Unit, University of Cape Town Lung Institute, Cape Town, South Africa
}

Corresponding author: C Day (cascia.day@uct.ac.za)

\begin{abstract}
Background. Delirium is associated with increased mortality and length of hospital stay. Limited data are available from HIV-infected acute hospital admissions in developing countries. We conducted a prospective study of delirium among acute medical admissions in South Africa (SA), a developing country with universal antiretroviral therapy (ART) access and high burdens of tuberculosis (TB) and non-communicable disease.

Objectives. To identify the prevalence of, risk factors for and outcomes of delirium in HIV-infected individuals in acute general medical admissions.

Methods. Three cohorts of adult acute medical admissions to Groote Schuur and Victoria Wynberg hospitals, Cape Town, SA, were evaluated for prevalent delirium within 24 hours of admission. Reference delirium testing was performed by either consultant physicians or neuropsychologists, using the Confusion Assessment Method.

Results. The study included 1182 acute medical admissions, with 318 (26.9\%) HIV-infected. The median (interquartile range) age and CD4 count were $35(30$ - 43) years and $132(61$ - 256) cells/ $\mu \mathrm{L}$, respectively, with 140/318 (44.0\%) using ART on admission. The prevalence of delirium was $17.6 \%$ (95\% confidence interval (CI) 13.7 - 22.1) among HIV-infected patients, and delirium was associated with increased inpatient mortality. In multivariable logistic regression analysis, factors associated with delirium were age $\geq 55$ years (adjusted odds ratio (aOR) 6.95 (95\% CI 2.03 - 23.67); $p=0.002$ ), and urea $\geq 15 \mathrm{mmol} / \mathrm{L}$ (aOR 4.83 (95\% CI 1.7 - 13.44); $p=0.003$ ), while ART use reduced risk $(p=0.014)$. A low CD4 count, an unsuppressed viral load and active TB were not predictors of delirium; nor were other previously reported risk factors such as non-opportunistic acute infections or polypharmacy.

Conclusions. Delirium is common and is associated with increased mortality in HIV-infected acute medical admissions in endemic settings, despite increased ART use. Older HIV-infected patients with renal dysfunction are at increased risk for inpatient delirium, while those using ART on admission have a reduced risk.
\end{abstract}

S Afr Med J 2021;111(10):974-980. https://doi.org/10.7196/SAMJ.2021.v111i10.15628

The prevalence of delirium in acute medical inpatients is high, with estimates ranging from $10 \%$ to $31 \% .{ }^{[1]}$ Short- and long-term complications of delirium include increased mortality and length of hospitalisation, post-discharge institutionalisation, and long-term functional and cognitive decline. ${ }^{[2]}$ This is a considerable healthcare burden: in developed countries the cost of delirium is equal to that of falls and diabetes mellitus. ${ }^{[3]}$ A number of risk factors for delirium have been identified, including predisposing factors such as dementia and advancing age and acute precipitating factors such as drugs, infections and metabolic abnormalities. ${ }^{[2]}$ Protective factors include a higher level of education, a marker of cognitive reserve. ${ }^{[4]}$ Unfortunately, the data on delirium outcomes and risk factors in general medical inpatients are derived almost exclusively from geriatric populations in developed countries, a very different population to acute medical admissions in developing country settings with a high HIV/tuberculosis (TB) burden ${ }^{[5]}$ Furthermore, the few studies from developing country settings such as sub-Saharan Africa (SSA) have either been conducted in medical patients aged
$>60$ years or in specialised populations, such as psychiatric and intensive care settings. ${ }^{[6-8]}$ In developed countries such as the USA, studies were done among HIV-infected populations before universal access to combination antiretroviral therapy (ART). ${ }^{[9-14]}$

HIV targets the central nervous system (CNS) with resultant neurocognitive impairment (NCI), a well-described predisposing risk factor for delirium. Acute and opportunistic infections (OIs), also known risk factors for delirium, occur more commonly with advancing immunosuppression. It is therefore unsurprising that studies have shown high prevalence rates of delirium (3.7 - 57\%) in HIV-infected populations. ${ }^{[6,11-13]}$ Delirium in HIV is often concomitant with NCI, in $8-22 \%$ of cases. ${ }^{[15]}$ Combination ART both prevents and improves NCI and decreases the incidences of acute and OIs. Widespread access to ART may therefore mitigate delirium risk. It is unclear whether HIV infection remains an independent risk factor for delirium in acute medical admissions in endemic HIV settings with universal ART programmes. ${ }^{[9]}$ Furthermore, in developing country settings such as South Africa (SA), with high 
burdens of communicable diseases (CDs) and non-communicable diseases (NCDs), clinicians do not know which delirium risk factors to identify among HIV-infected admissions. Available data almost exclusively predate universal ART access. ${ }^{[9-13,16]}$ Furthermore, data from SSA populations are highly variable, owing to a lack of standardised delirium testing methods or incomplete HIV testing. ${ }^{[6]}$

\section{Objectives}

We therefore conducted a study among acute medical admissions with a high HIV burden, using standardised delirium diagnostic testing methods, in a country with universal access to ART. The objectives were to identify the prevalence of, risk factors for and outcomes of delirium in HIV-infected individuals admitted to SA hospitals.

\section{Methods}

\section{Study design and participants}

This prospective cohort study focused on HIV-infected acute general medical admissions. The study was a secondary analysis within a parent prospective randomised cohort study designed for the development and validation of a novel four-question delirium screening tool. Prevalent delirium at admission was assessed using the Confusion Assessment Method (CAM) as the primary reference test to identify patients with delirium. A computer-generated random selection of daily acute general medical admissions to two hospitals (Groote Schuur Hospital (GSH) and Victoria Wynberg Hospital (VWH)) in Cape Town, SA, were enrolled for the parent study during two phases: 22 August 2009 - 10 December 2009 (development) and 11 November 2013 - 7 March 2014 (validation). GSH is a tertiary referral hospital with $\sim 150$ acute general medical admission beds, while VWH is a district-level hospital with $\sim 80$ acute general medical beds. All adult medical patients aged $\geq 18$ years admitted on weekdays were eligible, and a random sample of 10 patients per day was selected (usual daily patient intake 15 - 25 patients) to allow study staff to perform delirium testing within 24 hours of admission. Exclusion criteria were: (i) informed consent declined; (ii) age $<18$ years; (iii) Glasgow Coma Scale score $\leq 12$; and (iv) aphasia (Fig. 1).

The primary studies were approved by the University of Cape Town-Groote Schuur Hospital Human Research Ethics Committee (ref. no. 311/2017). If a patient was diagnosed with delirium during reference testing, their initial consent was not considered valid and the HREC granted an initial waiver of the informed consent requirement. When the patient's delirium had resolved, the study was explained to the patient again and written informed consent was obtained. If this was not possible as part of the initial inpatient admission, the patient and/or next of kin were contacted and arrangements were made to complete consent either in person or telephonically. If the patient was uncontactable, the HREC granted a waiver to allow the inclusion of patient data. There was no patient involvement.

All data relevant to the study are included in the article or have been uploaded as supplementary information (Appendices 1 - 5, available at http://samj.org.za/public/sup/15628.pdf).

\section{Delirium testing}

Within 24 hours of admission, a study physician reviewed the patient's charts and obtained data pertaining to the primary diagnosis, clinical background, admission medication, level of education

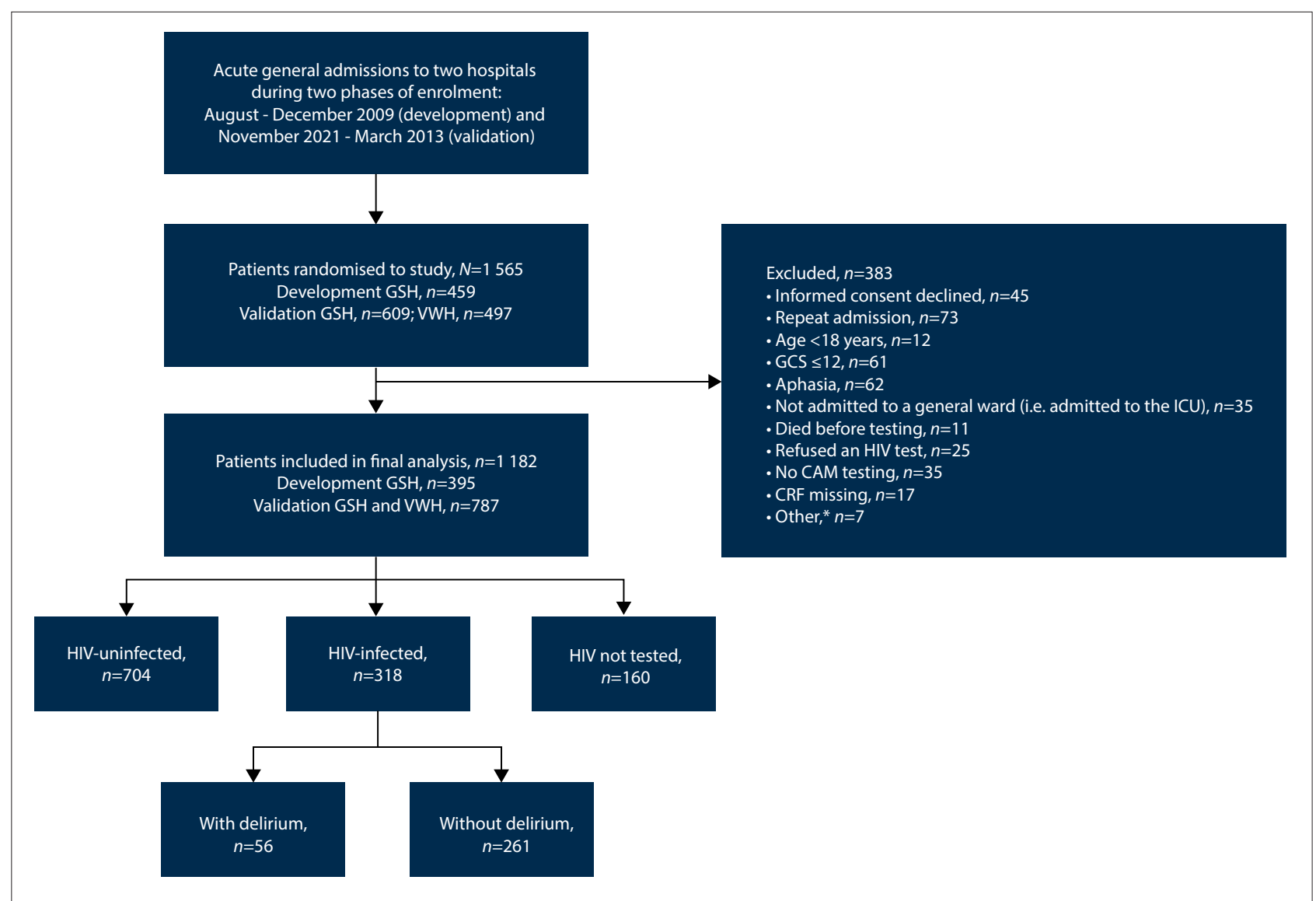

Fig. 1. Consort diagram. (GSH = Groote Schuur Hospital; VWH = Victoria Wynberg Hospital; GCS = Glasgow Coma Scale score; ICU = intensive care unit; CAM = Confusion Assessment Method; $C R F=$ case report form; ${ }^{\star}$ Language barrier, deaf, elective admission.) 
and demographic characteristics. A second independent study physician trained in delirium testing (in the development study) or a neuropsychologist (in the validation study) then assessed the patient for delirium using the CAM, performed during a 20 - 30-minute interview consisting of formal cognitive testing. ${ }^{[17]}$ For either testing tool the presence of language barriers was noted (see Fig. 1), or a ward-based translator was used when possible so that testing was performed in the patient's first language. Because delirium has, by its very nature, a fluctuating course of symptoms, patients were screened twice in 24 hours. However, there is still a possibility that some cases of delirium were missed owing to episodes of lucidity.

\section{HIV status, diagnostic, medication and outcome data acquisition and classification}

Investigations, including HIV screening and testing, were performed at the discretion of the attending physicians, and any patients who refused HIV testing during this admission were excluded from the study. Positive HIV status was defined as any record of a positive HIV test (either a rapid test or enzyme-linked immunosorbent assay) at any point prior to or during an index admission dating back to January 2005 (the earliest available information on the National Health Laboratory Service electronic system). The CD4 count and HIV viral load (VL) closest to or during the index admission, to a maximum of 12 months preceding admission, was included.

The patients' primary diagnoses and medications were collected by reviewing admission case records, pharmacy records and discharge summaries and assigning International Statistical Classification of Diseases and Related Health Problems, 10th revision (ICD-10) diagnosis codes. We analysed the association of delirium with the top five most frequent CDs and NCDs, considering known HIV-associated conditions separately. Categories of medications commonly linked to delirium were selected based on published literature, ${ }^{[18]}$ and all medications were assigned to groups as per the South African Medicines Formulary. Antiretrovirals (ARVs), anti-TB medication, and medication for prophylaxis of OIs (fluconazole and trimethoprim/sulfamethoxazole) were assessed as possible protective factors for delirium in HIV-infected patients. Detailed information on ICD-10 and medication groupings is provided in Appendices 1 and 2 (http://samj.org.za/public/sup/15628.pdf). Outcome mortality data were obtained from patient folders, the hospital electronic patient management system and the Western Cape Provincial death registry, which links a unique patient identification number with national death certificate records and system-wide electronic records.

\section{Statistical analysis}

Data were analysed in Stata 14.2 (StataCorp, USA). Categorical variables were summarised as frequencies and percentages. Sociodemographic and clinical characteristics and outcomes were assessed for differences between HIV-infected, HIV-uninfected, and HIV unknown patients overall and in those with delirium. The analysis was then restricted to HIV-infected patients $(n=318)$ to compare sociodemographics, clinical characteristics and outcomes between cases with and without delirium. Associations between categorical variables were analysed using the $\chi^{2}$ test and Fisher's exact test, as appropriate. The Wilcoxon rank-sum test or the KruskalWallis test were used to compare continuous variables between two and three groups, respectively.

Univariable and multivariable logistic regression analyses were performed to identify risk factors for delirium in HIV-infected patients. Variables analysed in univariable analysis were considered a priori, and receiver operating characteristic (ROC) curve analysis was used for age and urea to determine clinically relevant cut-off values. Variables were retained in the multivariable model if they were significantly associated with outcome $(p<0.05)$ and did not have sparse data (renal failure) or were not strongly collinear (urea and creatinine, total medication and ARVs). Education $\geq 7$ years and CD4 count were retained in the multivariable model regardless of significance owing to their clinical relevance. Odds ratios (ORs) were reported with $95 \%$ confidence intervals (CIs). A $p$-value $<0.05$ was regarded as statistically significant.

\section{Results}

A total of 1565 patients were randomised to the parent study (459 and 1106 in the development and validation phases, respectively) (Fig. 1). Of these, 383 were excluded and a total of 1182 patients were considered as part of this analysis. The prevalence of HIV infection was $26.9 \%(n=318 / 1182)$, with $44 \%$ ( $n=140 / 318)$ using ART on admission. Table 1 and Appendix 5 (http://samj.org.za/ public/sup/15628.pdf) describe the cohort stratified by HIV status and then restricted to only patients with delirium. Overall, the median (interquartile range (IQR)) age was 49.5 (34 - 63.2) years, and $53.1 \%$ were female (Table 1 ). HIV-infected patients were younger than the HIV-uninfected and unknown groups (median (IQR) 35 $(0$ - 43) years v. $52.7(38$ - 64.7) years and $66(55.5$ - 75.3) years, respectively; $p=0.0001$ ). The median (IQR) CD4 count was 132 (61 - 256) cells $/ \mu \mathrm{L}$. The prevalence of delirium was $17.6 \%$ in HIVinfected patients compared with $13.8 \%$ in HIV-uninfected patients and $11.9 \%$ in patients with unknown HIV status $(p=0.161)$. Overall inpatient and 12-month mortality was $6.2 \%(n=72 / 1 \quad 182)$ and $23.8 \%$ ( $n=281 / 1182$ ), respectively, with no difference by HIV status (Table 1). There was no loss to follow-up in either the inpatient or the 12-month mortality groups. Among HIV-positive patients (Table 2), delirium was associated with higher inpatient mortality (14.6\% v. 5.4\%; $p=0.036$ ), but although HIV-infected patients had a higher 12 -month mortality, the result was not significantly different $(33.9 \%$ v. $22.9 \% ; p=0.083$ ).

Table 1 and Appendix 5 (http://samj.org.za/public/sup/15628. pdf) show primary admission diagnoses, key laboratory parameters and the five most common admission medication categories. NCDs accounted for more hospital admissions than CDs (69.7\% v. $27.8 \%$; $p<0.0001$ ), and two distinct patient groups were evident. HIVinfected patients had low rates of NCDs and a high burden of $\mathrm{TB}$ and other CDs, such as meningitis/encephalitis. They also used more medication ( $15.1 \%$ on three or more medications) owing to the prescription of ARVs and greater use of anti-TB medication and antibiotics. In contrast, the older HIV-unknown group were predominantly admitted with NCDs, and non-steroidal anti-inflammatory and cardiac drug prescribing was higher than in HIV-positive patients $(p<0.0001)$. These differences were present when comparing the overall patient population (Table 1 ) and when restricted to patients with delirium (Appendix 5, http://samj.org. za/public/sup/15628.pdf). These findings show that HIV-infected patients have a unique profile relative to HIV-uninfected general medical admissions.

HIV-infected patients are compared in Table 2 according to the presence or absence of delirium. The two groups were similar in terms of age, gender and education status. With the exception of renal failure, there were no significant differences in CD or NCD primary diagnoses. Similarly, although patients with delirium had lower median CD 4 cell counts ( 104 cells $/ \mu \mathrm{L}$ (95\% CI 32 - 214) v. 150 cells $/ \mu \mathrm{L}$ (95\% CI 62 - 266); $p=0.1284$ ) and lower rates of HIV viral suppression $(27.3 \%$ v. $40 \% ; p=0.519)$, these differences were not statistically 
Table 1. Comparison of HIV-infected, HIV-uninfected and HIV unknown groups

\begin{tabular}{|c|c|c|c|c|c|}
\hline & All $(N=1182)$ & $\begin{array}{l}\text { HIV-infected } \\
(N=318)\end{array}$ & $\begin{array}{l}\text { HIV-uninfected } \\
(N=704)\end{array}$ & $\begin{array}{l}\text { HIV not tested } \\
(N=160)\end{array}$ & $p$-value \\
\hline Age (years), median (IQR) & $49.5(34-63.2)$ & $35(30-43)$ & $52.7(38-64.7)$ & $66(55.5-75.3)$ & 0.0001 \\
\hline Female, $n(\%)$ & $627(53.1)$ & $197(61.9)$ & $335(47.6)$ & $95(59.4)$ & $<0.0001$ \\
\hline Education $\geq 7$ years, $n(\%)$ & $830(75.9)$ & $230(72.3)$ & $488(74.9)$ & $112(74.2)$ & 0.332 \\
\hline Delirium present, $n(\%)$ & $172(14.6)$ & $56(17.6)$ & $97(13.8)$ & $19(11.9)$ & 0.161 \\
\hline Dementia/cognitive deficit, $n$ (\%) & $52(4.4)$ & $8(2.5)$ & $24(3.4)$ & $20(12.5)$ & $<0.0001$ \\
\hline \multicolumn{6}{|l|}{ Primary diagnosis, ${ }^{*} n(\%)(N=1$ 153) } \\
\hline NCDs total & $824(69.7)$ & $141(44.3)$ & $544(77.3)$ & $139(86.9)$ & $<0.0001$ \\
\hline \multicolumn{6}{|l|}{4 most common NCDs } \\
\hline CVS combined & $238(20.1)$ & $29(9.1)$ & $149(21.2)$ & $60(37.5)$ & $<0.0001$ \\
\hline Respiratory & $94(8.0)$ & $11(3.5)$ & $72(10.2)$ & $11(6.9)$ & 0.001 \\
\hline Cerebrovascular & $70(5.9)$ & $4(1.3)$ & $49(7.0)$ & $17(10.6)$ & $<0.0001$ \\
\hline Renal failure & $42(3.6)$ & $9(2.8)$ & $30(4.3)$ & $3(1.9)$ & 0.293 \\
\hline CDs total & $329(27.8)$ & $142(44.7)$ & $165(23.44)$ & $22(13.8)$ & $<0.0001$ \\
\hline \multicolumn{6}{|l|}{4 most common CDs } \\
\hline $\mathrm{TB}$, total & $145(12.3)$ & $92(28.9)$ & $51(7.2)$ & $2(1.3)$ & $<0.0001$ \\
\hline Pulmonary TB & $75(6.4)$ & $35(11)$ & $39(5.5)$ & $1(0.6)$ & $<0.0001$ \\
\hline TB meningitis & $20(1.7)$ & $15(4.7)$ & $5(0.7)$ & 0 & $<0.0001$ \\
\hline Disseminated TB & $33(2.8)$ & $28(8.8)$ & $5(0.7)$ & 0 & $<0.0001$ \\
\hline Pneumonia & $88(7.5)$ & $27(8.5)$ & $52(7.4)$ & $9(5.6)$ & 0.528 \\
\hline Meningitis/encephalitis & $21(1.8)$ & $11(3.5)$ & $9(1.3)$ & 0 & 0.040 \\
\hline UTI & $20(1.7)$ & 0 & $16(2.3)$ & $4(2.5)$ & 0.005 \\
\hline \multicolumn{6}{|l|}{ Laboratory results, median (IQR) } \\
\hline $\operatorname{WCC}\left(/ 10^{9} / \mathrm{L}\right)(n=1124)$ & $9.2(7.1-11.6)$ & $8(5.7-9.6)$ & $9.5(7.6-12.4)$ & $9.6(8.5-12.4)$ & 0.0001 \\
\hline $\mathrm{Hb}(\mathrm{g} / \mathrm{dL})(n=1122)$ & $11.3(9.4-13.8)$ & $9.8(8.5-11.7)$ & $12.1(9.6-14.1)$ & $12.7(9.8-14.4)$ & 0.0001 \\
\hline Sodium $(\mathrm{mmol} / \mathrm{L})(n=1$ 102) & $138(135-141)$ & $135(132-139)$ & $139(135-141)$ & $140(138-143)$ & 0.0001 \\
\hline Urea $(\mathrm{mmol} / \mathrm{L})(n=1$ 101) & $7.1(4.7-9.7)$ & $5.9(4-8.9)$ & $7.2(4.9-9.8)$ & $8.5(6.6-9.8)$ & 0.0001 \\
\hline \multicolumn{6}{|l|}{ Medication, $n(\%)$} \\
\hline Absolute number of medications $\geq 3$ & $90(7.6)$ & $48(15.1)$ & $28(4)$ & $14(8.8)$ & $<0.0001$ \\
\hline \multicolumn{6}{|l|}{5 most common admission medications ${ }^{\dagger}$} \\
\hline NSAIDs & $230(19.5)$ & $9(2.8)$ & $138(19.6)$ & $83(51.9)$ & $<0.0001$ \\
\hline Cardiac medications & $169(14.3)$ & $6(1.9)$ & $109(15.5)$ & $54(33.8)$ & $<0.0001$ \\
\hline Steroids & $131(11.1)$ & $11(3.5)$ & $101(14.4)$ & $19(11.9)$ & $<0.0001$ \\
\hline TB medications & $99(8.4)$ & $62(19.5)$ & $36(5.1)$ & $1(0.6)$ & $<0.0001$ \\
\hline Antibiotics & $62(5.3)$ & $49(15.4)$ & $13(1.9)$ & 0 & $<0.0001$ \\
\hline \multicolumn{6}{|l|}{ Mortality, $n(\%)$} \\
\hline Inpatient & $72(6.2)$ & $22(7.0)$ & $40(5.8)$ & $10(6.3)$ & 0.7540 \\
\hline 12 months & $281(23.8)$ & $79(24.8)$ & $167(23.7)$ & $35(21.9)$ & 0.7710 \\
\hline
\end{tabular}

significant. However, the delirium group had significantly lower haemoglobin $(p=0.0194)$ and higher urea $(p=0.0047)$ and creatinine levels $(p=0.0197)$. A higher number of patients without delirium were using three or more admission medications $(n=45 ; 17.2 \% \mathrm{v}$. $n=3 ; 5.4 \%$; $p=0.023$ ), with a greater number of patients on ARVs, antibiotics, and OI prophylaxis (trimethoprim/sulfamethoxazole and fluconazole). However, use of TB medication in the two groups was similar (19.6\% v. $19.5 \%$; $p=0.976)$.

Table 3 shows the univariable and multivariable logistic regression analysis used to analyse associations with prevalent delirium in HIV-infected acute medical admissions. For every 5 -year increase in age there was a $12 \%$ increased risk of delirium (95\% CI $0.99-1.30$; $p=0.065)$, with an adjusted odds ratio (aOR) of $6.95(2.03-23.67)$ using an ROC-selected age $\geq 55$ years $(p=0.002)$. On univariable analysis, both a primary diagnosis of renal failure (OR 6.3 (95\% CI 1.6 - 24.4); $p=0.007)$ and ROC-selected urea $\geq 15 \mathrm{mmol} / \mathrm{L}$ increased the risk of delirium, with only urea $>15 \mathrm{mmol} / \mathrm{L}$ retained in the multivariable analysis (aOR 4.83 (95\% CI 1.7 - 13.44); $p=0.0003$ ). Patients using three or more medications on admission had a decreased risk of delirium (OR 0.3 (95\% CI $0.1-0.9$ ); $p=0.035$ ), with the greatest protective effect from the use of ART on admission (aOR 0.34 (95\% CI $0.14-0.8) ; p=0.014)$. Other NCDs and CDs, including TB, or markers of advanced immunosuppression and poor HIV control (CD4 cell count and VL suppression), were not significant risk factors for delirium.

\section{Discussion}

Our study is the first to study delirium, using a validated testing method, among HIV-infected inpatients admitted in the context of an acute general medical intake in a developing country with dual CD 
Table 2. Comparison of HIV-infected groups with and without delirium

\begin{tabular}{|c|c|c|c|}
\hline & $\begin{array}{l}\text { HIV-infected with } \\
\text { delirium }(N=56)\end{array}$ & $\begin{array}{l}\text { HIV-infected without } \\
\text { delirium }(N=261)\end{array}$ & $p$-value \\
\hline Age (years), median (IQR) & $34(30-43.1)$ & $34.6(29.4-41.7)$ & 0.373 \\
\hline Female, $n(\%)$ & $33(58.9)$ & $164(62.6)$ & 0.608 \\
\hline Education $\geq 7$ years, $n(\%)$ & $28(73.7)$ & $202(79.8)$ & 0.385 \\
\hline \multicolumn{4}{|l|}{ Primary diagnosis $(N=337),{ }^{*} n(\%)$} \\
\hline Non-communicable total & $23(41.2)$ & $118(45.0)$ & 0.588 \\
\hline \multicolumn{4}{|l|}{4 most common NCDs } \\
\hline CVS combined & $2(3.6)$ & $27(10.3)^{\star *}$ & 0.131 \\
\hline Respiratory & 0 & $11(4.2)$ & 0.223 \\
\hline Renal failure & $5(8.9)$ & $4(1.5)$ & 0.010 \\
\hline Liver failure & 0 & $5(1.9)$ & 0.591 \\
\hline Communicable total & $28(50.0)$ & $114(43.5)$ & 0.375 \\
\hline \multicolumn{4}{|l|}{2 most common CDs } \\
\hline TB total & $18(32.1)$ & $74(28.2)$ & 0.559 \\
\hline Pulmonary TB & $5(8.9)$ & $30(11.5)$ & 0.814 \\
\hline TB meningitis & $4(7.1)$ & $11(4.2)$ & 0.312 \\
\hline Disseminated TB & $7(12.5)$ & $21(8)$ & 0.299 \\
\hline Pneumonia & $7(12.5)$ & $20(7.6)$ & 0.287 \\
\hline HIV-specific diagnoses, ${ }^{*} n(\%)$ & $10(17.9)$ & $44(16.8)$ & 0.847 \\
\hline \multicolumn{4}{|l|}{2 most common } \\
\hline $\mathrm{CCM}$ & $3(5.4)$ & $8(3.1)$ & 0.417 \\
\hline HAND & $4(7.14)$ & $6(2.29)$ & 0.079 \\
\hline \multicolumn{4}{|l|}{ Laboratory results, median (IQR) } \\
\hline CD4 (cells $/ \mu \mathrm{L})(n=302)$ & $104(32-214)$ & $150(62-266)$ & 0.1284 \\
\hline Viral suppression (\%) $(n=86)$ & $3(27.3)$ & $30(40)$ & 0.519 \\
\hline $\operatorname{WCC}\left(/ 10^{9} / \mathrm{L}\right)(n=309)$ & $8.3(5.9-9.7)$ & $8(5.7-9.5)$ & 0.6299 \\
\hline $\mathrm{Hb}(\mathrm{g} / \mathrm{dL})(n=308)$ & $9.5(8.1-10.3)$ & $9.8(8.7-12.1)$ & 0.0194 \\
\hline Sodium $(\mathrm{mmol} / \mathrm{L})(n=297)$ & $134.5(131-140)$ & $135(132-139)$ & 0.3279 \\
\hline Urea $(\mathrm{mmol} / \mathrm{L})(n=297)$ & $7.2(4.5-16.7)$ & $5.7(3.9-8.5)$ & 0.0047 \\
\hline Creatinine $(\mu \mathrm{mol} / \mathrm{L})(n=306)$ & $83(65-208)$ & $76(58-94)$ & 0.0197 \\
\hline CRP $(\mathrm{mg} / \mathrm{L})(n=185)$ & $76.2(28.9-135.2)$ & $45.7(20-107.1)$ & 0.3522 \\
\hline \multicolumn{4}{|l|}{ Admission medication,' $n(\%)$} \\
\hline Absolute number of medications $\geq 3$ & $3(5.4)$ & $45(17.2)$ & 0.023 \\
\hline ARVs & $14(25.0)$ & $126(48.1)$ & 0.002 \\
\hline Trimethoprim/sulfamethoxazole & $3(5.4)$ & $38(14.5)$ & 0.078 \\
\hline TB medications & $11(19.6)$ & $51(19.5)$ & 0.976 \\
\hline Antibiotics & $4(7.1)$ & $45(17.2)$ & 0.067 \\
\hline \multicolumn{4}{|l|}{ Mortality, $n(\%)$} \\
\hline Inpatient & $8(14.6)$ & $14(5.4)$ & 0.036 \\
\hline 12 months & $19(33.9)$ & $60(22.9)$ & 0.083 \\
\hline \multicolumn{4}{|c|}{ 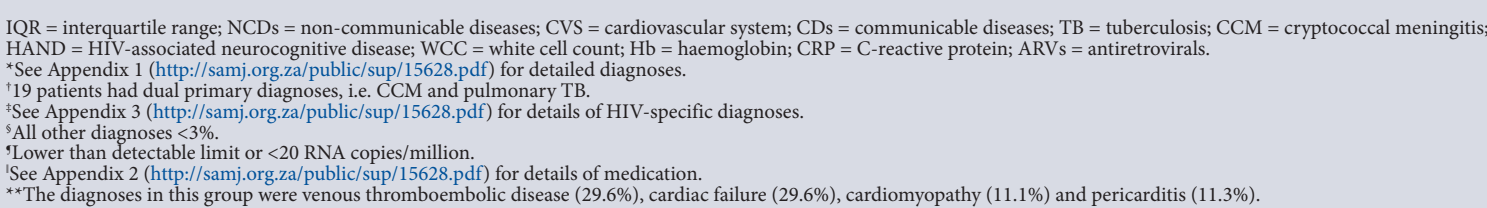 } \\
\hline
\end{tabular}

and NCD burdens, ${ }^{\left[{ }^{5]}\right.}$ and in the setting of improved access to ART. The key findings of our study are: (i) delirium occurred in 14.6\% of all acute medical hospital admissions and $17.6 \%$ of HIV-infected patients (with 44\% ART coverage); (ii) delirium was an independent risk factor for inpatient mortality among HIV-infected admissions; (iii) ART use at admission was protective against prevalent delirium; and (iv) age $\geq 55$ years and urea $>15 \mathrm{mmol} / \mathrm{L}$ were associated with an increased risk of delirium among HIV-infected admissions, rather than markers of advanced immunosuppression (low CD4 cell count), poor viral control (VL) or active TB. These findings should inform clinical practice for generalists and HIV clinicians in developing country settings by allowing them to rapidly identify HIV-infected patients at risk for prevalent delirium.

Delirium prevalence rates vary widely between studies and are dependent on the delirium screening tool used, the study population and patient demographics, the burden of disease, and whether the study took place in a developing or developed world setting. No data are available on HIV-infected medical inpatients in the ART era. Our cohort delirium prevalence of $17.6 \%$ in HIV-infected patients is consistent with both the $4-30 \%$ published in a recent 


\begin{tabular}{|c|c|c|c|c|}
\hline Variable & Univariable, OR $(95 \% \mathrm{CI})^{*}$ & $p$-value & Multivariable, aOR (95\% CI) & $p$-value \\
\hline Age (per 5-year increase) & $1.12(0.99-1.3)$ & 0.065 & & \\
\hline Age $\geq 55$ years & $4.1(1.6-11.1)$ & $<0.0001$ & $6.95(2.03-23.67)$ & 0.002 \\
\hline Education $\geq 7$ years & $0.71(0.3-1.6)$ & 0.386 & $0.76(0.3-1.95)$ & 0.583 \\
\hline \multicolumn{5}{|l|}{ Laboratory values } \\
\hline $\mathrm{CD} 4$ & $0.99(0.99-1)$ & 0.241 & $0.84(0.79-1.05)$ & 0.22 \\
\hline $\mathrm{Hb}$ & $0.9(0.8-0.98)$ & 0.025 & $0.91(0.79-1.05)$ & 0.22 \\
\hline Urea & $1(1-1.1)$ & 0.008 & & \\
\hline Urea $\geq 15 \mathrm{mmol} / \mathrm{L}$ & $5.0(2.3-10.7)$ & $<0.0001$ & $4.83(1.7-13.44)$ & 0.003 \\
\hline \multicolumn{5}{|l|}{ Medication } \\
\hline ARVs & $0.4(0.2-0.7)$ & 0.002 & $0.34(0.14-0.8)$ & 0.014 \\
\hline
\end{tabular}

$\mathrm{OR}=$ odds ratio; $\mathrm{CI}=$ confidence interval; $\mathrm{aOR}=$ adjusted $\mathrm{OR} ; \mathrm{Hb}=$ haemoglobin; $\mathrm{ARVs}=$ antiretrovirals.

${ }^{*} \mathrm{R}=$ odds ratio $\mathrm{CI}=$ confidence interval; $\mathrm{aOR}=$ adjusted $\mathrm{OR} ; \mathrm{Hb}=$ haemoglix 4 (http://samj.org.za/public/sup/15628.pdf) for detailed univariable analysis.

review on delirium in $\mathrm{SSA}^{[6]}$ and the $12-57 \%$ in US studies ${ }^{[12-15,19]}$ in HIV-infected medical inpatients in the pre-ART era. The delirium rate was high despite ART coverage of $44 \%$ in our cohort. Studies show that in general medical wards delirium goes undiagnosed in $32-67 \%$ of patients and that this group of patients has an increased mortality rate. ${ }^{[20]}$ Lalonde ${ }^{[11]}$ found that only one of 46 HIV-infected patients was correctly diagnosed with delirium in a specialist HIV centre. These figures together should continue to highlight that even as ART coverage continues to improve, delirium surveillance in developing countries is an important health priority. In the UK, the National Institute for Health and Care Excellence (NICE) recommends risk factor and indicator assessment for all patients admitted to hospital, ${ }^{[21]}$ and incident delirium is used as a marker of good clinical governance. ${ }^{[22]}$

We found that delirium was associated with increased inpatient mortality in HIV-infected patients as well as an (albeit non-significant) increase in 12-month mortality. This finding is in keeping with previous studies in older patients showing that delirium is related to significantly increased short- and long-term mortality. ${ }^{[23,24]}$ The mortality rates of our HIV-infected patients with delirium $333.9 \%$ at 12 months and $14.6 \%$ as inpatients) were far lower than the inpatient mortality rates reported by Uldall and colleagues ${ }^{[9.19]}$ in two studies on HIV-infected patients (63\% and $97 \%$, respectively), probably because our study was done in the era of universal access to ART. However, a significantly lower percentage of our HIV-infected patients with delirium were on ARVs at the time of admission compared with their non-delirious counterparts $(25.0 \%$ and $48.1 \%$, respectively). The protective effect of ART on delirium risk is not surprising, given its known benefit in terms of the NCI associated with HIV. ${ }^{[25]}$ These findings highlight the need to improve universal access to ART.

We found that older HIV-infected patients with acute renal dysfunction were at high risk for inpatient delirium, while those using ART on admission seemed to be protected. Similarly, on univariable analysis we found three known delirium risk factors to be important in our HIV-infected patients: older age, anaemia and uraemia. These findings are in keeping with data from Tanzanian and Indian general medical inpatient cohorts. ${ }^{[7,26]}$ Anaemia and uraemia are well-described risk factors for delirium, and anaemia is also a predictor of mortality in HIV-infected patients. ${ }^{[2,27]}$ Uraemia probably causes delirium as a result of uraemic encephalopathy, a poorly understood process that is thought to involve oxidative stress, hormonal and neurotransmitter imbalances, and the accumulation of toxic metabolites. ${ }^{[28]}$ However, in our cohort many typical risk factors (acute non-OIs, TB and hyponatraemia) were not predictors of delirium. We also found that markers of advanced HIV (low CD4 count and unsuppressed VL) were not significant risk factors for delirium, in keeping with the one previous study that assessed CD4 count. ${ }^{[9]}$

Interestingly, in our study we found that the more admission medications prescribed, the lower the risk of delirium. This high number of medications is probably attributable to the pill burden of combined ART and the requirement for OI antibiotic prophylaxis in HIV-infected patients. This finding is in clear contrast to the frequently reported link between polypharmacy and delirium in elderly populations; ${ }^{[2]}$ however, this increased risk was also reported in HIV-infected cohorts in which the use of three or more CNS active medications and medication side-effects were found to be key risk factors for delirium. ${ }^{[9,11]}$ Medications that significantly contributed to delirium in another study were benzodiazepines and narcotics; ${ }^{[19]}$ this was also not found in our study. Notably, all the above studies were in the pre-combination ART era ${ }^{[29]}$ and ART use was not reported.

\section{Study limitations}

The present study is to our knowledge the largest to date to conduct formalised delirium assessments in HIV-infected acute medical admissions. Nevertheless, despite the large overall study size, there were only 56 cases of delirium in the HIV-infected group. We therefore had limited power to detect small differences between groups, and the regression analysis findings should be interpreted with caution. Our findings will need validation in other developing HIV-endemic country settings. Another limitation was the lack of mandatory HIV testing on admission, leading to concern about possible inclusion bias. Fortunately, only $13.5 \%$ of patients were not tested for HIV in a large cohort, and there were few missing CD4 cell count data (but insufficient VL measurements). The HIV nottested cohort was a group of older patients with more NCDs, fewer infections and less TB, and thought likely to be at low risk of HIV infection by the attending clinicians. Although assessing prevalent delirium on admission may be difficult owing to incomplete available information as well as the fluctuating nature of the condition, a further period of observation would only be expected to increase this prevalence.

\section{Conclusions}

Delirium is highly prevalent and poorly recognised, and has high morbidity and mortality that carry a significant cost to healthcare systems. ${ }^{[3]}$ We have shown that even with improved ART coverage in a developing country setting with a dual burden of HIV and TB, 
delirium is common and is associated with inpatient mortality in HIV-infected patients. Clinicians need to be aware that ageing HIVinfected patients who are not on ART and who have renal failure are at risk for delirium. In addition, a low CD4 count and elevated VL do not increase the likelihood of delirium. Further delirium research using a standardised testing method is required to validate these findings in other developing countries.

Declaration. The research for this study was done in partial fulfilment of the requirements for CD's MMed (Medicine) degree at the University of Cape Town.

Acknowledgements. We thank Ms Yasmina Craven for all her assistance collecting the GSH data, Dr Clint Cupido, Dr Nasief van der Schyff, Mr Tony Martin, and Ms Fatima Gallow for their assistance in recruitment and testing at VWH, and Dr Nicki Tiffin from the Provincial Health Data Centre of the Western Cape Government for the linkage analysis.

Author contributions. JGP designed and led the development study. GC assisted with enrolling patients and collected data. JGP and PR designed and led the validation study. FA, KJ, LG and CD enrolled patients and collected data for the validation study. CD, FA and CA entered and collated the original data. CD and JGP designed and wrote the study protocol. $\mathrm{CD}$ and $\mathrm{KM}$ analysed and interpreted data. $\mathrm{CD}$ wrote the first draft of the report. MC assisted with parent study design and editing. All authors reviewed and approved the final version.

Funding. Neither this study nor the parent study were funded.

Conflicts of interest. None.

1. Siddiqi N, House AO, Holmes JD. Occurrence and outcome of delirium in medical in-patients: A systematic literature review. Age Ageing 2006;35(4):350-364. https://doi.org/10.1093/ageing/afl005 2. Inouye SK, Westendorp RG, Saczynski JS. Delirium in elderly people. Lancet 2014;383(9920):911-922. https://doi.org/10.1016/s0140-6736(13)60688-1

3. Leslie DL, Marcantonio ER, Zhang Y, Leo-Summers L, Inouye SK. One-year health care costs . Leslie DL, Marcantonio ER, Zhang Y, Leo-Summers L, Inouye SK. One-year health care costs
associated with delirium in the elderly population. Arch Intern Med 2008;168(1):27-32. https://doi. org/10.1001/archinternmed.2007.4

4. Jones RN, Yang FM, Zhang Y, Kiely DK, Marcantonio ER, Inouye SK. Does educational attainment contribute to risk for delirium? A potential role for cognitive reserve. J Gerontol 2006;61(12):13071311. https://doi.org/10.1093/gerona/61.12.1307

5. Lozano R, Naghavi M, Foreman K, et al. Global and regional mortality from 235 causes of death for 20 age groups in 1990 and 2010: A systematic analysis for the Global Burden of Disease Study 2010. Lancet 2012;380(9859):2095-2128. https://doi.org/10.1016/S0140-6736(12)61728-0

6. Paddick SM, Kalaria RN, Mukaetova-Ladinska EB. The prevalence and clinical manifestations of delirium in sub-Saharan Africa: A systematic review with inferences. J Neurol Sci 2015;348(1-2):6-17. https://doi.org/10.1016/j.jns.2014.10.034
7. Lewis EG, Banks J, Paddick SM, et al. Risk factors for delirium in older medical inpatients in Tanzania. Dement Geriatr Cogn Disord 2017;44(3-4):160-170. https://doi.org/10.1159/000479058

8. Kwizera A, Nakibuuka J, Ssemogerere L, et al. Incidence and risk factors for delirium among mechanically ventilated patients in an African intensive care setting: An observational multicenter mechanically ventilated patients in an African intensive care setting: An observa
study Crit Care Res Pract 2015;2015:491780. https://doi.org/10.1155/2015/491780

9. Uldall KK, Harris VL, Lalonde B. Outcomes associated with delirium in acutely hospitalised acquired Uldall KK, Harris VL, Lalonde B. Outcomes associated with delirium in acutely hospitalised acquired
immune deficiency syndrome patients. Compr Psychiatry 2000;41(2):88-91. https://doi.org/10.1016/ immune deficiency syn

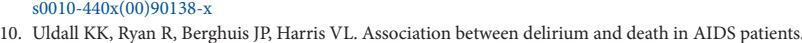
AIDS Patient Care STDs 2000;14(2):95-100. https://doi.org/10.1089/108729100318037

11. Lalonde B. Delirium in AIDS patients: Discrepancy between occurrence and health care provide identification. AIDS Patient Care STDs 1996;10(5):282-287. https://doi.org/10.1089/apc.1996.10.282

12. Breitbart W, Marotta R, Platt MM, Weisman H. A double-blind trial of haloperidol, chlorpromazine, and lorazepam in the treatment of delirium in hospitalised AIDS patients. Am J Psychiatry 1996;153(2):231-237. https://doi.org/10.1176/ajp.153.2.23

13. Fernandez F, Levy JK, Mansell PWA. Management of delirium in terminally ill AIDS patients. Int J Psychiatry Med 1990;19(2):165-172. https://doi.org/10.2190/fwjp-2ypc-jpfa-lm3n

14. Bialer PA, Wallack JJ, Prenzlauer SL, Bogdonoff L, Wilets I. Psychiatric comorbidity among hospitalised AIDS patients vs. non-AIDS patients referred for psychiatric consultation. Psychosomatics 1996;37(5):469-475. https://doi.org/10.1016/s0033-3182(96)71535-9

15. Munjal S, Ferrando SJ, Freyberg Z. Neuropsychiatric aspects of infectious diseases. Crit Care Clin 2008;33(3):681-712. https://doi.org/10.1016/j.ccc.2017.03.007

16. Trickey A, May MT, Vehreschild J-J, et al. Survival of HIV-positive patients starting antiretroviral therapy between 1996 and 2013: A collaborative analysis of cohort studies. Lancet HIV 2017;4(8):e349-e56. https://doi.org/10.1016/S2352-3018(17)30066-8

17. Joint United Nations Programme on HIV/AIDS (UNAIDS). HIV and Aging: A special supplemen to the UNAIDS report on the global AIDS epidemic 2013. UNAIDS, 2013. https://reliefweb.int/ report/world/hiv-and-aging-special-supplement-unaids-report-global-aids-epidemic-2013 (accessed 10 December 2017).

18. Gaudreau J-D, Gagnon P, Roy M-A, Harel F, Tremblay A. Association between psychoactive medications and delirium in hospitalised patients: A critical review. Psychosomatics 2005;46(4):302316. https://doi.org/10.1176/appi.psy.46.4.302

19. Uldall KK, Berghuis JP. Delirium in AIDS patients: Recognition and medication factors. AIDS Patient Care STDs 1997;11(6):435-441. https://doi.org/10.1089/apc.1997.11.435

20. Mittal D, Majithia D, Kennedy R, Rhudy J. Differences in characteristics and outcome of delirium as based on referral patterns. Psychosomatics 2006;47(5):367-375. https://doi.org/10.1176/appi. psy.47.5.367

21. Young J, Anderson D, Gager M. Delirium: diagnosis, prevention and management. National Institute for Health and Care Excellence, 2010. https://www.nice.org.uk/guidance/cg103/evidence/fullguideline-pdf-134653069 (accessed 10 December 2017).

22. Inouye SK, Schlesinger MJ, Lydon TJ. Delirium: A symptom of how hospital care is failing older persons and a window to improve quality of hospital care. Am J Med 1999;106(5):565-573. https://do org/10.1016/s0002-9343(99)00070-4

23. Todd OM, Teale EA. Delirium: A guide for the general physician. Clin Med 2017;17(1):48-53. https:// doi.org/10.7861/clinmedicine.17-1-48

24. Kukreja D, Günther U, Popp J. Delirium in the elderly: Current problems with increasing geriatric age. Indian J Med Res 2015;142(6):655-662. https://doi.org/10.4103/0971-5916.174546

25. Habib AG, Yakasai AM, Owolabi LF, et al. Neurocognitive impairment in HIV-1-infected adults in sub-Saharan Africa: A systematic review and meta-analysis. Int J Infect Dis 2013;17(10):e820-e831. sub-Saharan Africa: A systematic review
https://doi.org/10.1016/j.ijid.2013.06.011

26. Grover S, Ghormode D, Ghosh A, et al. Risk factors for delirium and inpatient mortality with delirium . Grover S, Ghormode D, Ghosh A, et al. Risk factors for delirium and inpatient mo
J Postgrad Med 2013;59(4):263-270. https://doi.org/10.4103/0022-3859.123147

27. Johannessen A, Naman E, Ngowi BJ, et al. Predictors of mortality in HIV-infected patients starting antiretroviral therapy in a rural hospital in Tanzania. BMC Infect Dis 2008;8(1):52. https://do org/10.1186/1471-2334-8-52

28. Scaini G, Ferreira GK, Streck EL. Mechanisms underlying uremic encephalopathy. Rev Bras Ter Intensiva 2010;22(2):206-211.

29. Vella S, Schwartländer B, Sow SP, Eholie SP, Murphy RL. The history of antiretroviral therapy and of its implementation in resource-limited areas of the world. AIDS 2012;26(10):1231-1241. https://doi. org/10.1097/qad.0b013e32835521a3

Accepted 28 May 2021 